\title{
Decreases in self-reported alcohol consumption following HIV counseling and testing at Mulago Hospital, Kampala, Uganda
}

Judith A Hahn ${ }^{1 *}$, Robin Fatch ${ }^{1}$, Rhoda K Wanyenze ${ }^{2}$, Steven Baveewo ${ }^{3}$, Moses R Kamya ${ }^{2}$, David R Bangsberg ${ }^{4}$ and Thomas J Coates ${ }^{5}$

\begin{abstract}
Background: Alcohol use has a detrimental impact on the HIV epidemic, especially in sub-Saharan Africa. HIV counseling and testing $(\mathrm{HCT})$ may provide a contact opportunity to intervene with hazardous alcohol use; however, little is known about how alcohol consumption changes following HCT.

Methods: We utilized data from 2056 participants of a randomized controlled trial comparing two methods of HCT and subsequent linkage to HIV care conducted at Mulago Hospital in Kampala, Uganda. Those who had not previously tested positive for HIV and whose last HIV test was at least one year in the past were eligible. Participants were asked at baseline when they last consumed alcohol, and prior three month alcohol consumption was measured using the Alcohol Use Disorders Identification Test - Consumption (AUDIT-C) at baseline and quarterly for one year. Hazardous alcohol consumption was defined as scoring $\geq 3$ or $\geq 4$ for women and men, respectively. We examined correlates of alcohol use at baseline, and of hazardous and non-hazardous drinking during the year of follow-up using multinomial logistic regression, clustered at the participant level to account for repeated measurements.
\end{abstract}

Results: Prior to HCT, 30\% were current drinkers (prior three months), 27\% were past drinkers (>3 months ago), and $44 \%$ were lifetime abstainers. One-third (35\%) of the current drinkers met criteria for hazardous drinking. Hazardous and non-hazardous self-reported alcohol consumption declined after $\mathrm{HCT}$, with $16 \%$ of baseline current drinkers reporting hazardous alcohol use 3 months after HCT. Independent predictors $(p<0.05)$ of continuing non-hazardous and hazardous alcohol consumption after HCT were sex (male), alcohol consumption prior to HCT (hazardous), and HIV status (negative). Among those with HIV, non-hazardous drinking was less likely among those taking antiretroviral therapy (ART).

Conclusions: HCT may be an opportune time to intervene with alcohol consumption. Those with HIV experienced greater declines in alcohol consumption after $\mathrm{HCT}$, and non-hazardous drinking decreased for those with HIV initiating ART. HCT and ART initiation may be ideal times to intervene with alcohol consumption. Screening and brief intervention (SBI) to reduce alcohol consumption should be considered for HCT and HIV treatment venues.

Keywords: Alcohol, Africa, HIV, HIV counseling and testing, Antiretroviral therapy, Screening and brief intervention

\footnotetext{
* Correspondence: Judy.hahn@ucsf.edu

1 University of California, San Francisco, Box 0886, San Francisco, CA 94143-0886, USA

Full list of author information is available at the end of the article
}

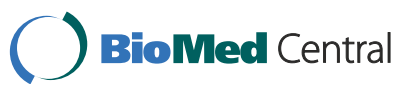

(c) 2014 Hahn et al.; licensee BioMed Central Ltd. This is an Open Access article distributed under the terms of the Creative Commons Attribution License (http://creativecommons.org/licenses/by/4.0), which permits unrestricted use, distribution, and reproduction in any medium, provided the original work is properly credited. The Creative Commons Public Domain Dedication waiver (http://creativecommons.org/publicdomain/zero/1.0/) applies to the data made available in this article, unless otherwise stated. 


\section{Background}

Heavy alcohol consumption is known to have detrimental effects on health, accounting for approximately $4.5 \%$ of the global burden of disease and injury world-wide [1]. Heavy alcohol use is a common and growing problem in sub-Saharan Africa (SSA). In Uganda, heavy alcohol consumption among drinkers is especially common [1]. Among male drinkers, the per capita yearly pure alcohol consumption is 25.6 liters; among female drinkers, the per capita yearly pure alcohol consumption is 19.6 liters [1].

Sub-Saharan Africa is home to nearly $70 \%$ of the global HIV infections (UNAIDS report 2011), and the heavy alcohol consumption in this region exacerbates the problem for multiple reasons [2]. First, alcohol consumption and drinking venue attendance in SSA have been associated with increased HIV risk behaviors, such as number of sexual partners, unprotected sex, and commercial sex work $[3,4]$, as well as prevalent $[5,6]$ and incident HIV infection [7-9]. Alcohol consumption has also been associated with decreased access to HIV testing [10]. In addition, several studies of alcohol administration to macaques demonstrated increased SIV disease progression [11]; however, observational studies of heavy alcohol consumption and HIV disease progression in humans have yielded mixed results [12-14]. Finally, alcohol consumption is consistently associated with decreased antiretroviral therapy (ART) adherence in western countries [15], and increasingly in SSA [16-23], and heavy alcohol consumption has been associated with decreased retention in care [24].

We recently found that self-reported alcohol consumption by persons with HIV decreased concurrently with ART initiation in rural Uganda; almost two-thirds (64\%) of drinkers at baseline reported becoming and remaining abstinent for the duration of follow-up, for a median of 3.25 years [25]. Most became abstinent within three months of starting ART, suggesting that ART initiation may be an important time to intervene to reduce alcohol consumption. Reductions in alcohol use among women in a multicenter HIV cohort study in the United States have also been reported [26]. However, changes in alcohol use earlier in the course of HIV care, that is, after HIV counseling and testing (HCT), have not been examined. Because alcohol appears to play an important role in HIV transmission, reducing alcohol consumption early in the course of HIV could have an important impact on the HIV epidemic. HCT provides a point of health care contact that might be an opportune time to intervene on heavy alcohol consumption [27]. Current standard HCT guidelines, e.g. those published by the United States Centers for Disease Control and Prevention [28], recommend addressing the use of alcohol or drugs before sexual activity, but alcohol use itself is not directly addressed. Declines in sexual risk behavior due to HCT have been demonstrated [29], and it is plausible that other general health improvements might additionally occur after HCT.

For the above reasons, we sought to examine changes in alcohol use in the year following HCT. We utilized data collected in a randomized controlled trial of HCT methods and enhanced linkage to HIV care at Mulago Hospital in Kampala, Uganda [30] to examine whether alcohol use declined in the year following HCT. We examined whether changes in alcohol consumption differed by HIV status and sex, and examined demographic and other factors as predictors of hazardous and nonhazardous drinking following HCT. Among those with HIV, we examined whether CD4 cell count at baseline and initiation of ART were associated with declines in drinking after $\mathrm{HCT}$.

\section{Methods}

This study is an analysis of data collected as part of a randomized controlled trial comparing an abbreviated method of HCT to traditional full length HCT, and, among those with HIV, comparing an enhanced protocol for linkage to HIV care to standard linkage to care. Study details, including a detailed flow diagram, have been presented elsewhere [30].

\section{Study population}

Participants were recruited from May 2008 to June 2011 from inpatient medical wards and outpatient clinics (including emergency and casualty wards, medical outpatient clinics, and sexually transmitted disease clinics) at Mulago Hospital in Kampala, Uganda. Eligibility criteria included being $\geq 18$ years old, residing within $25 \mathrm{~km}$ of Mulago Hospital with no plans of moving, having never tested positive for HIV, having last tested HIV-negative at least one year prior, and being willing to receive an HIV test and engage in study procedures. All participants provided informed consent prior to study participation and the study was approved by the institutional review boards of Makerere University, Uganda National Council for Science and Technology, University of California Los Angeles, and University of California San Francisco.

\section{Study visits and procedures}

All participants completed a 30-minute, intervieweradministered survey at baseline. Participants were then randomly assigned (1:1) to receive either traditional HCT (45 minutes), or an abbreviated (15 minutes) version of HCT. Following HCT and determination of HIV status, participants were randomized a second time. To retain a roughly equivalent number of HIV-positive and HIV-negative participants followed for one year, HIV- 
negative participants were randomized to follow-up or no follow-up (roughly 1:1). HIV-positive participants were randomized to receive enhanced or standard linkage to HIV care (1:1); all were followed for one year. Follow-up study interviews were conducted quarterly for one year, and included assessment of HIV care and ART status, alcohol consumption, and sexual behaviors within the past three months.

\section{Dependent variables}

Alcohol use prior to baseline was examined using four categories: lifetime abstainer, past drinker (drank $>3$ months prior), current (prior three months) non-hazardous drinker, and current (prior three months) hazardous drinker. We defined hazardous drinking using the Alcohol Use Disorders Identification Test - Consumption (AUDIT-C) [31] with a cut-off of $\geq 3$ for women and $\geq 4$ for men; non-hazardous drinking was defined as any current drinking that did not reach the AUDIT-C cut-off. Following HCT, drinking in the prior three months among those reporting current drinking at baseline was examined as: none, non-hazardous drinking and hazardous drinking, as defined above.

\section{Covariates}

Covariates of interest included demographics: participant sex, age, marital status, education, occupation, and religion. We created a household wealth index to group households based on ownership of durable goods, housing quality, and energy sources [32]. This variable was divided into three categories: low (0-40\%), middle (41$80 \%)$, and high (81-100\%) household wealth. We asked about frequency of household hunger: sometimes/often (>2 times/month), seldom (1-2 times/month), or never. We included site of recruitment (inpatient ward, outpatient clinic, or emergency/casualty ward) as a potential proxy for participant health. We examined social support using the Oslo Social Support scale [33], and categorized participants as having poor (score of 3-8), moderate (9-11), or strong (12-14) social support. We also examined whether any household members consumed alcohol in the past three months. Reason(s) for HIV testing were also examined; while the questionnaire allowed a participant to endorse more than one reason, we created a hierarchical variable from these reasons: (a) concerned about health/symptoms, (b) wanted to plan for the future or just wanted to know one's status, and (c) other reasons. Among those with HIV, ART status was ascertained using a list of medications at each follow-up interview. We also included HCT study arm (traditional or abbreviated) and, among those with HIV, linkage to HIV care study arm (enhanced or standard), in the analyses of alcohol use in the year following HCT.

\section{Laboratory testing}

HIV testing was conducted using a serial testing procedure using rapid antibody tests as described previously [34]. HIV testing was conducted at Mulago Hospital; CD4 cell count testing for those with HIV infection was conducted at the Makerere University-Johns Hopkins University laboratory.

\section{Statistical analysis}

We calculated frequency distributions for categorical variables, and medians and interquartile ranges (IQR) for continuous variables. We conducted unadjusted and adjusted multinomial logistic regression analyses for the baseline outcomes (lifetime abstainer, past drinker, current non-hazardous drinker, and current hazardous drinker). Among those who were current drinkers at baseline, we also conducted unadjusted and adjusted multinomial logistic regression analyses of alcohol use in the one year following $\mathrm{HCT}$, clustering on the participant to account for the repeated measures over time. We included the study arms (HCT arm and, among those with HIV, HIV linkage to care arm) as covariates only in the analyses of alcohol use in the year following $\mathrm{HCT}$, as study randomization occurred after the baseline interview. The levels of the outcome variable were: no alcohol use in the past three months, current nonhazardous use, and current hazardous use. For each of these models, we used a purposeful selection technique [35] to create multivariable models. Covariates were initially included if they were associated in bivariate models with a $\mathrm{p}$-value $\leq 0.25$; they were then excluded in a backwards stepwise fashion, keeping variables in the model if they were associated at $\mathrm{p} \leq 0.10$. Next, any covariates initially excluded based on the cut-off of $\mathrm{p} \leq 0.25$ were included one by one, and their significance was re-assessed. They were retained in the final model if $\mathrm{p} \leq 0.10$.

Next, to determine whether the time trends varied by HIV status or sex in our model of alcohol consumption following HCT, we conducted tests of interaction of those two variables with time in the multivariable models, one at a time, while adjusting for the other variables in the model [36]. As there was a significant interaction with HIV status and time $(\mathrm{p}=0.02)$, and because we were interested in examining variables relevant only to HIV-positive participants, we also fit a multivariable model among only the participants with HIV, using the purposeful selection methods described above, and additionally allowing baseline CD4 cell count, linkage to care study arm, and ART use to enter the model.

Data were missing at baseline and follow-up (15\% of observations had at least one missing value; 13\% of follow-up study visits were missing), so we conducted multiple imputation using chained equations. The results 
using the imputed data were similar to the results using listwise deletion; therefore we present the results using the imputed data for the regression analyses.

\section{Results}

\section{Participant characteristics}

3389 participants were enrolled in the main study; HIV prevalence was $30 \%(\mathrm{n}=1003) .1323$ HIV negatives were randomized to no follow-up, and 10 participants were missing data on baseline alcohol use; therefore 2056 participants were included in the baseline analysis. More than half of the participants (57\%) were female (Table 1), median age was 30 years (IQR: 25-38), and approximately half $(49 \%)$ had more than a primary education. Approximately one-third (32\%) of participants were Catholic, 31\% were Protestant, 19\% were Moslem, and $18 \%$ were Saved, Pentecostal, or another religion. Eighteen percent (18\%) of participants reported having at least one household member who had consumed alcohol in the past three months. Most participants reported that their household never went hungry $(76 \%)$ and that they had moderate or strong social support (81\%). The median CD4 cell count among those who were infected with HIV was 285 cells $/ \mathrm{mm}^{3}$ (IQR: 132-463).

\section{Baseline alcohol use}

Approximately $56 \%$ of the sample had ever consumed any alcohol. Of the 1154 participants who reported ever taking alcohol, 607 (53\%) reported taking alcohol in the prior three months. Among former drinkers, alcohol was last consumed 3-12 months ago for 215 participants (39\%). Among current (prior three months) drinkers, $40 \%$ of men and $30 \%$ of women reported hazardous alcohol use, as defined by the AUDIT-C.

Table 2 shows the results from multinomial logistic regression of past, current non-hazardous, and current hazardous alcohol use compared to lifetime abstention. Independent correlates $(\mathrm{p}<0.05)$ of past alcohol use versus lifetime abstention were: age ( $>35$ years), religion (Protestants more likely than Moslems), marital status (previously married more likely than currently married), household hunger (never hungry less likely than sometimes/often hungry), any alcohol use by household members, and HIV status (positive). Independent correlates of current, non-hazardous alcohol use versus lifetime abstention were: sex (male), age (26-35 years), religion (Catholics more likely than Protestants; Moslems and Saved/Pentecostal/others less likely than Protestants), household wealth (medium household wealth more likely than low), and any alcohol use by household members. Lastly, independent predictors of current, hazardous alcohol consumption compared to lifetime abstention were: sex (male), age (older), religion (Moslems and Saved/Pentecostal/others less likely than Protestants), social support (strong support more likely than moderate support), any alcohol use by household members, recruitment at an outpatient clinic (versus an inpatient ward), and HIV status (positive). The relative risk ratios (RRR) increased in size across the categories from past drinking, to current non-hazardous drinking, to current hazardous drinking for sex, age, and having a household member who consumes alcohol.

\section{Alcohol use in the year following HCT}

Among current drinkers at baseline, both hazardous and non-hazardous alcohol consumption decreased dramatically in the first three months after HCT for those with and without HIV infection (Figure 1). Loss to follow-up between hazardous and non-hazardous drinkers at baseline was similar; overall, $8 \%$ of hazardous drinkers and $8 \%$ of non-hazardous drinkers had no follow-up interviews. Study interview completion at 3, 6, 9, and 12 months was $89 \%, 85 \%, 86 \%$ and $86 \%$ respectively, for those categorized as non-hazardous drinkers at baseline, and $89 \%, 86 \%, 84 \%$ and $85 \%$ respectively, for those categorized as hazardous drinkers at baseline.

Among current drinkers at baseline, independent predictors $(\mathrm{p}<0.05)$ of current, non-hazardous drinking compared to no drinking in the year following HCT were: sex (male), hazardous alcohol use at baseline, and HIV status (negative) (Table 3). These variables were also independent predictors of current, hazardous drinking compared to no drinking, in addition to follow-up month (less hazardous drinking at 9 months). HCT study arm was not associated with non-hazardous or hazardous drinking during follow-up.

In multivariable regression limited to current drinkers at baseline with HIV (Table 4), independent predictors of current, non-hazardous alcohol use after HCT were: sex (male) and ART status (on ART more likely to not drink). Independent predictors of current, hazardous alcohol consumption after HCT among those with HIV were: hazardous alcohol use at baseline, and recruitment at an emergency/casualty ward (less hazardous drinking compared to those recruited at an inpatient ward). Linkage to care and HCT study arms were not associated with non-hazardous or hazardous drinking during follow-up.

\section{Discussion}

In a large sample of persons receiving HCT in Uganda, almost one-third reported current alcohol use, and onethird of those met criteria for hazardous alcohol consumption. Among current drinkers, both hazardous and non-hazardous drinking declined dramatically in the first three months after HCT, and the decline was more dramatic among those with HIV. In the year following HCT, continued drinking at both hazardous and non- 
Table 1 Baseline demographic and behavioral characteristics of participants undergoing HCT in Kampala, Uganda

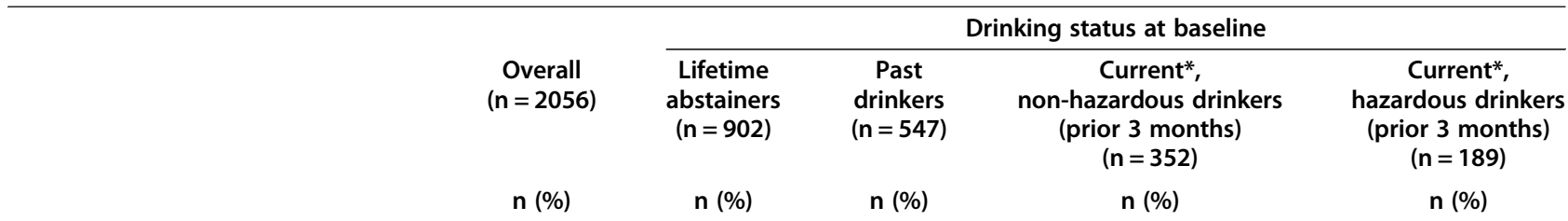

Gender

$\begin{array}{rrrrrr}\text { Male } & 879(42.8) & 351(38.9) & 222(40.6) & 165(46.9) & 108(57.1) \\ \text { Female } & 1177(57.3) & 551(61.1) & 325(59.4) & 187(53.1) & 81(42.9)\end{array}$

Age (overall median: 30; IQR: 25-38)

$\begin{array}{rlllll}18-25 & 580(28.2) & 321(35.6) & 130(23.8) & 86(24.4) & 26(13.8) \\ 26-35 & 852(41.4) & 353(39.1) & 212(38.8) & 162(46.0) & 94(49.7) \\ >35 & 624(30.4) & 228(25.3) & 205(37.5) & 104(29.6) & 69(36.5)\end{array}$

Education

\section{Primary education or less \\ More than primary education}

Occupation

$$
\text { Laborer }
$$$$
\text { Business/Sales/Technical }
$$$$
\text { Other }
$$

Religion

Protestant
Catholic
Moslem

$$
\text { Saved/Pentecostal/Other }
$$

Marital status

Married
Married in the past
Never married

$1043(50.8)$

$$
439 \text { (48.7) }
$$

278 (50.9)

$462(51.3)$

268 (49.1)

668 (32.5)

285 (31.6)

186 (34.0)

$901(43.8)$

388 (43.1)

$240(43.9)$

486 (23.7)

228 (25.3)

$121(22.1)$

$$
629 \text { (30.6) }
$$

217 (24.1)

161 (29.4)

651 (31.7)

198 (22.0)

176 (32.2)

398 (19.4)

$283(31.4)$

64 (11.7)

378 (18.4)

204 (22.6)

146 (26.7)

$$
866(42.1)
$$

$370(41.0)$

212 (38.8)

656 (31.9)

$248(27.5)$

208 (38.1)

$533(25.9)$

$284(31.5)$

126 (23.1)

Household wealth

How often do household members go hungry?

$$
\begin{array}{r}
\text { Sometimes/Often } \\
\text { ( }>2 \text { times/month) } \\
\text { Seldom (1-2 times/month) }
\end{array}
$$

Never

$295(14.6)$
$200(9.9)$
$1522(75.5)$

103 (11.6)

$$
66(7.5)
$$

246 (45.2)

207 (38.1)

91 (16.7)

717 (80.9)

108 (20.1)

$61(11.4)$

368 (68.5)

Social support

$$
\begin{array}{r}
\text { Strong support } \\
\text { Moderate support } \\
\text { Poor support }
\end{array}
$$$$
274 \text { (13.9) }
$$$$
107 \text { (12.2) }
$$$$
81 \text { (15.8) }
$$$$
628(71.9)
$$$$
325(63.4)
$$

$139(15.9)$

107 (20.9)

Recruitment site

$380(19.3)$

$$
\text { Inpatient wards }
$$$$
400 \text { (19.5) }
$$$$
181(20.1)
$$$$
106 \text { (19.4) }
$$$$
378(69.1)
$$

119 (33.8)

54 (28.6)

$151(42.9)$

$91(48.2)$

$82(23.3)$

44 (23.3)

135 (38.4)

88 (46.6)

169 (48.0)

76 (40.2)

$30(8.5)$

$17(9.0)$

18 (5.1)

8 (4.2)

159 (45.2)

92 (48.7)

116 (33.0)

65 (34.4)

77 (21.9)

32 (16.9)

144 (40.9)

96 (50.8)

155 (44.0)

72 (38.1)

53 (15.1)

$21(11.1)$

$\begin{array}{ll}36(10.4) & 35(19.7) \\ 254(73.6) & 86(48.3) \\ 55(15.9) & 57(32.0)\end{array}$


Table 1 Baseline demographic and behavioral characteristics of participants undergoing HCT in Kampala, Uganda (Continued)

\begin{tabular}{|c|c|c|c|c|c|}
\hline \multicolumn{6}{|l|}{$\begin{array}{l}\text { Reasons for HIV testing } \\
\text { (illness }>\text { planning }>\text { other) }\end{array}$} \\
\hline $\begin{array}{l}\text { AIDS symptoms/concern } \\
\text { about current illness }\end{array}$ & $652(31.7)$ & $241(26.7)$ & $201(36.8)$ & $117(33.2)$ & $70(37.0)$ \\
\hline $\begin{array}{r}\text { Just wanted to know/plan } \\
\text { for future }\end{array}$ & $1312(63.8)$ & $624(69.2)$ & $320(58.5)$ & $225(63.9)$ & $105(55.6)$ \\
\hline Other & $92(4.5)$ & $37(4.1)$ & $26(4.8)$ & $10(2.8)$ & $14(7.4)$ \\
\hline \multicolumn{6}{|l|}{$\begin{array}{l}\text { Any household members consumed } \\
\text { alcohol, past } 3 \text { months }\end{array}$} \\
\hline None & $1671(82.0)$ & $805(89.4)$ & $439(81.5)$ & $276(79.5)$ & $108(57.8)$ \\
\hline Any & $367(18.0)$ & 95 (10.6) & $100(15.6)$ & $71(20.5)$ & $79(42.3)$ \\
\hline \multicolumn{6}{|l|}{ Last time consumed alcohol } \\
\hline Never & $902(43.9)$ & $902(100.0)$ & $0(0.0)$ & $0(0.0)$ & $0(0.0)$ \\
\hline$>5$ years ago & $191(9.3)$ & $0(0.0)$ & $191(34.9)$ & $0(0.0)$ & $0(0.0)$ \\
\hline $1-5$ years ago & $141(6.9)$ & $0(0.0)$ & $141(25.8)$ & $0(0.0)$ & $0(0.0)$ \\
\hline 3 months -1 year ago & $215(10.5)$ & $0(0.0)$ & $215(39.3)$ & $0(0.0)$ & $0(0.0)$ \\
\hline Prior 3 months & $607(29.5)$ & $0(0.0)$ & $0(0.0)$ & $352(100.0)$ & $189(100.0)$ \\
\hline AUDIT-C at baseline (median (IQR)) & $0(0-1)$ & & & & \\
\hline \multicolumn{6}{|l|}{ HIV status } \\
\hline HIV Negative & 1058 (51.5) & $529(58.7)$ & $250(45.7)$ & $176(50.0)$ & 71 (37.6) \\
\hline HIV Positive & 998 (48.5) & 373 (41.4) & $297(54.3)$ & $176(50.0)$ & $118(62.4)$ \\
\hline \multicolumn{6}{|l|}{$\begin{array}{l}\text { Baseline CD4 cell count among } \\
\text { those with HIV (cells/mm }{ }^{3} \text { ) } \\
\text { (overall median: } 285 \text {; IQR: } 132-463 \text { ) }\end{array}$} \\
\hline$<200$ & $359(36.1)$ & $139(37.3)$ & $122(41.4)$ & $53(30.1)$ & 35 (29.9) \\
\hline 200-349 & $233(23.4)$ & 85 (22.8) & $66(22.4)$ & $44(25.0)$ & $29(24.8)$ \\
\hline $350-499$ & $202(20.3)$ & 74 (19.8) & $60(20.3)$ & 34 (19.3) & $26(22.2)$ \\
\hline$>=500$ & $200(20.1)$ & $75(20.1)$ & 47 (15.9) & $45(25.6)$ & $27(23.1)$ \\
\hline
\end{tabular}

${ }^{*} \mathrm{n}=66$ current drinkers were unable to be classified as hazardous or non-hazardous drinkers.

hazardous levels, as compared to abstinence, was more likely among men, and those who were not infected with HIV. Among those with HIV, current non-hazardous drinking was less likely among those on ART.

Our findings on lifetime and current alcohol consumption are consistent with those of prior studies of alcohol use in SSA. Alcohol use has previously been reported to be less common among women in Uganda [1], and alcohol use is prohibited in the Moslem and Evangelical religions. Persons with HIV in our study were more likely to have ever consumed alcohol (HIV status was associated with past and current hazardous use), which is consistent with the increasing evidence of a link between alcohol consumption and HIV infection [6]. We additionally found that household alcohol use was associated with current hazardous and non-hazardous alcohol use at baseline, with increased risk for hazardous use. This suggests that peer norms play a role in alcohol consumption, as has been shown among adolescents and college students [37]. In a previous study conducted in Uganda, less loneliness and higher levels of social interactions were associated with an increased frequency of alcohol use, suggesting that alcohol consumption is socially normative [38].

The decline in self-reported alcohol consumption during follow-up is consistent with our previous finding of high levels of self-reported abstinence just prior to and immediately following the start of ART in a cohort of persons initiating ART in rural southwest Uganda [25]. The current findings extend the literature by examining a key period in the time course of HIV infection, that is, prior to HCT and in the year immediately following HCT. Selfreported alcohol consumption declined most dramatically in the first three months following HCT, and additional declines occurred among those with HIV, at least among non-hazardous drinkers, when ART was initiated.

There are several plausible explanations for the decreases in alcohol consumption. First, alcohol consumption may 
Table 2 Multinomial logistic regression of past, current non-hazardous, and current hazardous drinking status at baseline compared to lifetime abstaining

\begin{tabular}{|c|c|c|c|c|c|c|}
\hline & \multicolumn{2}{|c|}{$\begin{array}{l}\text { Past drinking } \\
\text { RRR }(95 \% \mathrm{Cl})\end{array}$} & \multicolumn{2}{|c|}{$\begin{array}{c}\text { Current, non-hazardous drinking } \\
\text { RRR }(95 \% \mathrm{Cl})\end{array}$} & \multicolumn{2}{|c|}{$\begin{array}{c}\text { Current, hazardous drinking } \\
\text { RRR }(95 \% \mathrm{Cl})\end{array}$} \\
\hline & Bivariable & Multivariable & Bivariable & Multivariable & Bivariable & Multivariable \\
\hline \multicolumn{7}{|l|}{ Gender } \\
\hline Female & 1.00 & 1.00 & 1.00 & 1.00 & 1.00 & 1.00 \\
\hline Male & $1.07(0.86,1.33)$ & $1.25(0.98,1.60)$ & $1.40(1.10,1.77)$ & $1.57(1.19,2.07)$ & $2.10(1.52,2.89)$ & $2.86(1.96,4.16)$ \\
\hline \multicolumn{7}{|l|}{ Age (years) } \\
\hline $18-25$ & 1.00 & 1.00 & 1.00 & 1.00 & 1.00 & 1.00 \\
\hline $26-35$ & $1.48(1.14,1.93)$ & $1.28(0.95,1.73)$ & $1.69(1.27,2.25)$ & $1.42(1.01,1.99)$ & $3.23(2.05,5.08)$ & $2.62(1.53,4.50)$ \\
\hline$>35$ & $2.22(1.68,2.93)$ & $1.94(1.39,2.71)$ & $1.66(1.21,2.27)$ & $1.33(0.89,1.98)$ & $3.62(2.25,5.84)$ & $2.83(1.55,5.18)$ \\
\hline
\end{tabular}

Education

$$
\begin{array}{rc}
\text { Primary education or less } & 1.00 \\
\text { More than primary } & 0.92(0.74,1.13) \\
\text { education } &
\end{array}
$$

Occupation

$$
\begin{array}{rc}
\text { Laborer } & 1.00 \\
\text { Business/sales/technical } & 0.95(0.74,1.21) \\
\text { Other } & 0.81(0.61,1.08)
\end{array}
$$

Religion

$\begin{array}{rcc}\text { Protestant } & 1.00 & 1.00 \\ \text { Catholic } & 1.20(0.90,1.60) & 1.19(0.88,1.60) \\ \text { Moslem } & 0.30(0.22,0.43) & 0.32(0.23,0.45) \\ \text { Saved/Pentecostal/Other } & 0.96(0.72,1.29) & 1.08(0.79,1.47)\end{array}$

Married

Previously married

Never married

Household assets

$\begin{array}{rcc}\text { Low } & 1.00 & 1.00 \\ \text { Medium } & 1.00(0.79,1.26) & 1.18(0.91,1.52) \\ \text { High } & 1.06(0.78,1.44) & 1.21(0.87,1.68)\end{array}$

How often do household members go hungry?

$$
\begin{aligned}
& \text { Sometimes/Often } \\
& \text { (>2 times/month) }
\end{aligned}
$$$$
\text { Seldom (1-2 times/month) }
$$$$
\text { Never }
$$

Social support

$$
\begin{array}{r}
\text { Strong support } \\
\text { Moderate support } \\
\text { Poor support }
\end{array}
$$

$$
1.00
$$

$0.90(0.58,1.39)$

$0.82(0.52,1.31)$

$0.49(0.36,0.66) \quad 0.59(0.42,0.82)$
1.00

$0.82(0.65,1.05)$

1.00

$0.93(0.71,1.22)$

$0.81(0.59,1.12)$

1.00
$1.39(1.04,1.85)$
$0.16(0.11,0.25)$
$0.14(0.08,0.23)$

1.00

$1.05(0.80,1.39)$

$0.63(0.47,0.85)$

1.00

$1.30(1.01,1.69)$

$1.13(0.80,1.61)$

1.00
$1.35(1.01,1.81)$
$0.17(0.11,0.26)$
$0.15(0.09,0.24)$

1.00

$1.19(0.87,1.64)$

$0.72(0.50,1.04)$
1.00

$0.81(0.59,1.12)$

1.00

$1.24(0.86,1.79)$

$1.01(0.65,1.55)$

$$
1.00
$$

1.00

$0.92(0.64,1.32) \quad 0.84(0.57,1.24)$

$0.14(0.08,0.24) \quad 0.16(0.09,0.30)$

$0.09(0.04,0.19) \quad 0.12(0.05,0.25)$

$\begin{array}{cc}1.00 & 1.00 \\ 1.05(0.73,1.49) & 1.51(1.00,2.28) \\ 0.44(0.28,0.68) & 0.83(0.48,1.44)\end{array}$

1.00

$1.48(1.11,1.96)$

1.00

1.00

$1.31(0.89,1.91)$

$0.89(0.64,1.24) \quad 1.22(0.84,1.78)$

$0.64(0.39,1.07) \quad 0.75(0.43,1.29)$

Any household members consumed alcohol, past 3 months

$\begin{array}{ccccccc}\text { None } & 1.00 & 1.00 & 1.00 & 1.00 & 1.00 & 1.00 \\ \text { Any } & 1.92(1.42,2.60) & 1.80(1.29,2.50) & 2.32(1.68,3.21) & 1.95(1.36,2.79) & 6.24(4.33,8.99) & 5.74(3.80,8.67)\end{array}$


Table 2 Multinomial logistic regression of past, current non-hazardous, and current hazardous drinking status at baseline compared to lifetime abstaining (Continued)

Recruitment site

$\begin{array}{rcccccc}\text { Inpatient wards } & 1.00 & 1.00 & 1.00 & 1.00 & 1.00 & 1.00 \\ \text { Outpatient clinics } & 1.06(0.81,1.39) & 1.09(0.81,1.46) & 1.00(0.74,1.36) & 1.07(0.77,1.48) & 1.25(0.83,1.89) & 1.63(1.03,2.57) \\ \text { Emergency/casualty wards } & 0.95(0.64,1.41) & 0.84(0.56,1.26) & 1.35(0.90,2.03) & 1.34(0.87,2.08) & 0.88(0.47,1.62) & 1.01(0.52,1.98)\end{array}$

Reasons for HIV testing

Just wanted to know/plan
for future

AIDS symptoms/concern about current illness

Other $1.37(0.82,2.30)$
1.00

$1.63(1.29,2.05)$
1.00

$1.39(1.08,1.80)$

$0.92(0.48,1.75)$
1.00

$1.67(1.20,2.34)$

$2.25(1.18,4.30)$

HIV status

\begin{tabular}{rcccccc} 
HIV negative & 1.00 & 1.00 & 1.00 & 1.00 & 1.00 & 1.00 \\
HIV positive & $1.68(1.36,2.09)$ & $1.49(1.17,1.88)$ & $1.42(1.12,1.80)$ & $1.15(0.88,1.51)$ & $2.34(1.70,3.22)$ & $1.88(1.30,2.73)$ \\
\hline
\end{tabular}

RRR: Relative risk ratio.

$\mathrm{Cl}$ : Confidence interval.

have declined as a result of the precipitating factors that led the participants to seek health care services at Mulago Hospital. In our previous study, those with lower health scores were more likely to become abstinent [25], and health conditions have been previously cited as a reason for attempts to reduce or abstain from alcohol use [39-41]. Those seeking health care may represent a select group, i.e. they may be those who are currently ready and willing to engage in health-preserving behavior in general, or may be those who are too ill to drink. Perhaps the health condition serves as a "learnable moment", in which the patient recognizes a link between their health and drinking, which spurs reductions in drinking independent of any intervention [42]. In addition, contact with health care providers may be an intervention in itself. In a study of patients in residential drug and alcohol detoxification programs, receipt of primary care was associated with a significant decrease in alcohol use severity [43]. The counseling included during the HCT provided by this study may also have been an intervention, although neither of the two counseling protocols (traditional or abbreviated) explicitly addressed alcohol use. However, there were no differences in alcohol use after HCT by method of counseling, suggesting no effect of HCT counseling. The majority $(80 \%)$ of those who were infected with HIV received follow-up care [30], and the ISS clinic at Mulago Hospital discourages all alcohol consumption, especially at ART initiation. In addition, men who consume more than 14 drinks per week and women who consume more than 11 drinks per week, and lighter drinkers who do not quit drinking, are referred to a psychiatrist for counseling. This may explain the greater decrease in drinking among those with HIV, and especially among patients on ART. ART initiation may have a variety of health benefits beyond the direct effects on HIV disease. It has been found to be associated with other positive health outcomes, such as reduced internalized stigma [44], increased food security, nutritional status, physical health status [45], and decreased depression status [46]. If alcohol consumption declined for the reasons noted above, then these findings suggest that hospital and clinic entry, $\mathrm{HCT}$, and for those infected with HIV, ART initiation, may be opportune times to intervene on alcohol use, and future interventions should capitalize on these opportunities. Just as emergency

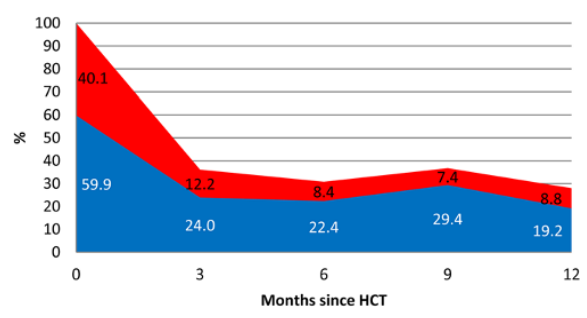

a $\quad$ HIV+ non-hazardous drinking $\quad * H I V+$ hazardous drinking

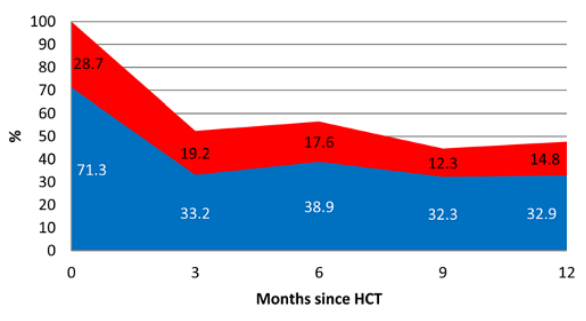

b IIIV-non-hazardous drinking $\quad$ HIV- hazardous drinking

Figure 1 Hazardous and non-hazardous drinking at study visits following HIV counseling and testing (HCT), among current drinkers at baseline, by HIV status. 1a. 294 HIV infected drinkers. 1b. 247 HIV negative drinkers. 
Table 3 Multinomial logistic regression of non-hazardous and hazardous drinking compared to no current drinking in the year following HCT, among baseline drinkers

\begin{tabular}{|c|c|c|c|c|}
\hline & \multicolumn{2}{|c|}{ Non-hazardous drinking RRR $(95 \% \mathrm{Cl})$} & \multicolumn{2}{|c|}{ Hazardous drinking RRR $(95 \% \mathrm{Cl})$} \\
\hline & Bivariable & Multivariable & Bivariable & Multivariable \\
\hline \multicolumn{5}{|l|}{ Gender } \\
\hline Female & 1.00 & 1.00 & 1.00 & 1.00 \\
\hline Male & $1.95(1.50,2.53)$ & $1.81(1.39,2.35)$ & $2.07(1.43,2.99)$ & $1.83(1.26,2.65)$ \\
\hline
\end{tabular}

Age (years)

$\begin{array}{cc}18-25 & 1.00 \\ 26-35 & 0.94(0.67,1.32) \\ >35 & 1.15(0.80,1.66)\end{array}$

1.00

$0.94(0.59,1.51)$

$1.11(0.67,1.84)$

Education

Primary education or less More than primary education

Occupation
Laborer Business/sales/technical

Other Religion

$$
\begin{array}{r}
\text { Protestant } \\
\text { Catholic } \\
\text { Moslem } \\
\text { Saved/Pentecostal/Other }
\end{array}
$$

Marital status

$$
\begin{array}{r}
\text { Married } \\
\text { Previously married } \\
\text { Never married }
\end{array}
$$

Household assets

$$
\begin{array}{r}
\text { Low } \\
\text { Medium } \\
\text { High }
\end{array}
$$

How often do household members go hungry?

$$
\begin{array}{r}
\text { Sometimes/Often (>2 times/month) } \\
\text { Seldom (1-2 times/month) }
\end{array}
$$$$
\text { Never }
$$

Social support

$$
\begin{array}{r}
\text { Strong support } \\
\text { Moderate support }
\end{array}
$$$$
\text { Poor support }
$$

Hazardous alcohol use at baseline?

$$
\begin{aligned}
& \text { No } \\
& \text { Yes }
\end{aligned}
$$

Any household members consumed alcohol, past 3 months

$$
\begin{array}{cc}
\text { None } & 1.00 \\
\text { Any } & 1.22(0.91,1.64)
\end{array}
$$

$1.09(0.72,1.65)$

1.00
1.00

$1.37(0.95,1.95)$

1.00

$1.37(0.89,2.10)$

$1.32(0.78,2.25)$

1.00

$1.00(0.68,1.47)$

$0.89(0.46,1.74)$

$0.82(0.36,1.90)$

1.00

$0.69(0.45,1.04)$

$1.04(0.65,1.66)$

1.00

$1.07(0.73,1.57)$

$1.20(0.68,2.13)$

1.00

$1.24(0.61,2.50)$

$1.13(0.66,1.93)$

$0.97(0.66,1.41)$

1.00

$0.89(0.52,1.52)$

$1.03(0.56,1.89)$

1.00

1.00

$2.40(1.65,3.51)$

$2.68(1.81,3.96)$

1.00

$1.48(1.01,2.16)$ 
Table 3 Multinomial logistic regression of non-hazardous and hazardous drinking compared to no current drinking in the year following HCT, among baseline drinkers (Continued)

Recruitment site

\author{
Inpatient wards \\ Outpatient clinics \\ Emergency/casualty wards
}

Reasons for HIV testing

Just wanted to know/plan for future

AIDS symptoms/concern about current illness

HIV status

$$
\begin{aligned}
& \text { HIV negative } \\
& \text { HIV positive }
\end{aligned}
$$

HCT arm

$$
\begin{aligned}
& \text { Abbreviated HCT } \\
& \text { Traditional HCT }
\end{aligned}
$$

Follow-up month
Other

$$
1.00
$$

$1.02(0.71,1.46)$

$0.67(0.41,1.10)$

1.00

$0.85(0.64,1.12)$

$1.06(0.62,1.82)$

1.00

$0.52(0.40,0.68)$

1.00

$1.01(0.77,1.31)$

3 months
6 months
9 months
12 months
1.00

$1.06(0.83,1.34)$

$1.08(0.84,1.39)$

$0.80(0.62,1.04)$
1.00

$0.90(0.56,1.44)$

$0.41(0.20,0.83)$

1.00

$0.88(0.59,1.32)$

$1.44(0.64,3.26)$
1.00

$0.49(0.37,0.65)$

$0.45(0.31,0.65)$

$0.40(0.27,0.58)$

1.00

$0.86(0.60,1.23)$

1.00

1.00

$0.81(0.59,1.10)$

$0.63(0.44,0.90)$

$0.80(0.58,1.11)$

$1.05(0.82,1.35)$

$1.07(0.83,1.39)$

$0.79(0.60,1.03)$ department visits for alcohol-related trauma provide a "learnable moment" for alcohol reduction, HCT may also provide such an opportunity.

However, it is also possible that the reductions in alcohol use are due to assessment reactivity. Assessment reactivity occurs when the assessment of alcohol consumption itself increases self-awareness of alcohol problems and thus triggers reductions in alcohol consumption [47]. A related explanation could be the Hawthorne effect, in which those being studied change their behavior. Either of these effects could explain the trends towards decreasing alcohol consumption seen in other prospective research studies, including a study in women with HIV and a study of injecting drug users in the United States [26,48]; however, they do not explain why the decreases were greater in those with HIV versus those without. Another reason for the decline in drinking may be regression to the mean, whereby by selecting the current drinkers at baseline, some revert to non-drinking on subsequent visits. However, one would expect an equal fraction of non-drinkers to become drinkers, and this was not the case (only $13 \%$ of non-drinkers at baseline reported any drinking at follow-up).

\section{Limitations}

The most important limitation is that the measures of drinking are self-reported, and under-report is a reasonable concern. Socially desirable reporting of stigmatized behavior is a common problem in health care settings. Those with HIV were likely to have been instructed to cease drinking during their HIV clinic visits, and might fear that ART may be denied if they report drinking [49]. We have previously reported on the use of biomarkers to detect under-reported alcohol use in Uganda [50,51]; however, we were unable to collect biological markers to corroborate self-report in this study. Nonetheless, the correlates of baseline and follow-up drinking were consistent with previous literature; for example, men drinking and Moslems not drinking, which alleviates some of this concern. Another limitation is that the study was not designed to examine alcohol consumption; therefore, we were unable to explore psycho-social correlates of drinking after HCT. An additional limitation is that we did not collect data on drug use, and thus are unable to comment on any changes in drug use that may have occurred following HCT. However, drug use in Uganda is uncommon; as reported by the World Health Organisation, $<1 \%$ of men and women in Uganda in 2004 had a drug use disorder [52]. Similarly, in a study of HIV-positive and HIV-negative female sex workers in Kampala, a group one would suspect would have high levels of drug use, only $8 \%$ reported ever using marijuana or khat, and only 2 women $(0.2 \%)$ had ever injected heroin, while $78 \%$ of women reported alcohol use [53]. Therefore, it is likely that very few of the participants 
Table 4 Multinomial logistic regression of non-hazardous and hazardous drinking compared to no current drinking in the year following HCT, among HIV infected baseline drinkers

\begin{tabular}{|c|c|c|c|c|}
\hline & \multicolumn{2}{|c|}{$\begin{array}{l}\text { Current, non-hazardous drinking } \\
\text { RRR }(95 \% \mathrm{Cl})\end{array}$} & \multicolumn{2}{|c|}{$\begin{array}{c}\text { Current, hazardous drinking } \\
\text { RRR }(95 \% \mathrm{Cl})\end{array}$} \\
\hline & Bivariable & Multivariable & Bivariable & Multivariable \\
\hline \multicolumn{5}{|l|}{ Gender } \\
\hline Female & 1.00 & 1.00 & 1.00 & 1.00 \\
\hline Male & $1.93(1.32,2.82)$ & $1.92(1.31,2.82)$ & $1.65(0.96,2.86)$ & $1.42(0.78,2.56)$ \\
\hline
\end{tabular}

Age (years)

\begin{tabular}{|c|c|c|}
\hline $18-25$ & 1.00 & 1.00 \\
\hline $26-35$ & $1.00(0.62,1.59)$ & $0.76(0.38,1.55)$ \\
\hline$>35$ & $1.21(0.70,2.08)$ & $0.80(0.35,1.81)$ \\
\hline
\end{tabular}

Education

Primary education or less More than primary education

Occupation

Laborer Business/sales/technical

Other

Religion

$\begin{array}{rc}\text { Protestant } & 1.00 \\ \text { Catholic } & 0.87(0.58,1.29) \\ \text { Moslem } & 0.66(0.32,1.34) \\ \text { Saved/Pentecostal/Other } & 0.49(0.18,1.37)\end{array}$

Married

Previously married

Never married

Household assets

$\begin{array}{rc}\text { Low } & 1.00 \\ \text { Medium } & 1.04(0.69,1.56) \\ \text { High } & 0.91(0.50,1.64)\end{array}$

How often do household members go hungry?

$$
\begin{array}{r}
\text { Sometimes/Often } \\
\text { ( }>2 \text { times/month) }
\end{array}
$$$$
\text { Never }
$$

Social support

$$
\begin{array}{r}
\text { Strong support } \\
\text { Moderate support } \\
\text { Poor support }
\end{array}
$$

Hazardous alcohol use at baseline?

$$
\begin{aligned}
& 0.59(0.36,0.96) \\
& 0.69(0.38,1.25)
\end{aligned}
$$

1.00

$1.25(0.72,2.16)$

$$
1.00
$$

$0.96(0.53,1.74)$

$1.14(0.55,2.35)$

$$
1.00
$$

$0.83(0.47,1.45)$

$0.46(0.15,1.48)$

$0.86(0.24,3.01)$

$$
1.00
$$

$0.92(0.51,1.64)$

$1.51(0.70,3.24)$

$$
1.00
$$

$1.20(0.67,2.15)$

$1.60(0.75,3.43)$

$$
1.00
$$

$1.00(0.41,2.46)$

$0.85(0.43,1.69)$

$$
1.00
$$

$0.58(0.28,1.19)$

$0.90(0.41,1.99)$

1.00

1.00

1.00

$1.42(0.91,2.23)$ 
Table 4 Multinomial logistic regression of non-hazardous and hazardous drinking compared to no current drinking in the year following HCT, among HIV infected baseline drinkers (Continued)

Any household members consumed alcohol, past 3 months

$\begin{array}{cc}\text { None } & 1.00 \\ \text { Any } & 1.04(0.68,1.59)\end{array}$

Recruitment site

$$
\begin{array}{r}
\text { Inpatient wards } \\
\text { Outpatient clinics } \\
\text { Emergency/casualty wards }
\end{array}
$$

Reasons for HIV testing

Just wanted to know/plan for future

AIDS symptoms/concern about current illness

Other

HCT arm

$$
\begin{aligned}
& \text { Abbreviated HCT } \\
& \text { Traditional HCT }
\end{aligned}
$$

Linkage to care arm

Enhanced linkage to care

Standard linkage to care

Follow-up month

3 months
6 months
9 months
12 months

Baseline CD4 count

Taking ART?

$\begin{array}{rc}<200 & 1.00 \\ 200-349 & 1.59(0.94,2.68) \\ 350-499 & 1.81(1.03,3.18) \\ >=500 & 1.60(0.95,2.71)\end{array}$

1.00

$1.04(0.62,1.75)$

$0.52(0.27,1.01)$

1.00

$0.84(0.57,1.24)$

$1.50(0.64,3.49)$

1.00

$0.96(0.66,1.41)$

1.00

$0.97(0.67,1.42)$

1.00

$0.83(0.56,1.21)$

$1.27(0.88,1.84)$

$0.69(0.47,1.01)$

1.00

$0.52(0.36,0.76)$
1.00

$1.09(0.65,1.83)$

$0.57(0.29,1.13)$

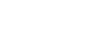

1.00

$1.40(0.80,2.46)$

$2.71(0.93,7.92)$

1.00

$1.01(0.59,1.72)$

1.00

$0.98(0.57,1.67)$

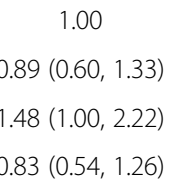

$0.83(0.54,1.26)$

1.00

1.00

$0.65(0.40,1.08)$

$0.68(0.40,1.16)$

$0.75(0.42,1.36)$

$0.84(0.45,1.57)$

$0.78(0.48,1.26)$

$0.88(0.52,1.49)$

\begin{tabular}{lccccc} 
& No & 1.00 & 1.00 & 1.00 & 1.00 \\
& Yes & $0.52(0.36,0.76)$ & $0.50(0.33,0.76)$ & $0.68(0.38,1.21)$ & $0.61(0.33,1.13)$ \\
\hline RRR: Relative risk ratio. &
\end{tabular}

$\mathrm{Cl}$ : Confidence interval.

were illicit drug users. Another limitation is that our results may not be generalizable to other populations in SSA. For example, a study in South Africa of HIV-infected patients on ART found a higher proportion of hazardous drinking among ever drinkers (75\% of men and $55 \%$ of women, as defined using AUDIT cutoffs of $\geq 8$ for men and $\geq 6$ for women) than was observed in our study [54]. A population-based study in Botswana, defining heavy drinking as $>14$ drinks/week for women and $>21$ drinks/ week for men, also found a higher proportion of heavy drinking (54\% of men and $58 \%$ of women) than among drinkers in our study [55]. Social controls may be stronger in Uganda than some SSA countries; HIV patients in particular in Uganda may be more compliant to the advice they receive from health care workers than patients in other countries. Thus, our results should be interpreted with caution when applied to other settings. Further study of how alcohol consumption changes after HCT in other countries in SSA would be valuable.

\section{Conclusions}

Despite these limitations, our findings significantly extend the previous literature of alcohol use in Uganda and SSA, to examine patterns in self-reported alcohol 
consumption prior to and after HIV testing. The findings suggest that HIV testing and ART initiation may be ideal venues for brief interventions. Screening and brief intervention (SBI) have been found to be efficacious in reducing alcohol consumption among those in primary care [56]; however, it is unknown whether such findings translate to resource-constrained settings [56]. Further work is needed to determine whether such interventions will be efficacious and whether they may be feasible to implement in SSA.

\section{Abbreviations}

AUDIT-C: Alcohol Use Disorders Identification Test - Consumption; ART: Antiretroviral therapy; Cl: Confidence interval; HCT: HIV counseling and testing; RRR: Relative risk ratio; SBI: Screening and brief intervention; SSA: Sub-Saharan Africa.

\section{Competing interests}

The authors declare that they have no competing interests.

\section{Authors' contributions}

$\mathrm{TC}, \mathrm{DB}, \mathrm{MK}, \mathrm{RW}$, and JH designed the study. JH and RF conducted the statistical analyses. JH drafted the manuscript, with input from all authors. SB, RW, and RF led the acquisition of the data. All authors read and approved the final manuscript.

\section{Acknowledgements}

We gratefully acknowledge the statistical advice of Dr. Stephen Shiboski. The data collection was funded by National Institutes of Health (NIH) R01 MH077512 which funded the work of authors JH, RF, RW, SB, MK, and TC for this study. Additional support was provided to $\mathrm{JH}$ (NIH R01 AA018631, U01AA020776, and K24 AA022586) and DB (NIH K24 MH087227) in the writing of the manuscript. The funder played no role in the design of the study, "the collection, analysis, and interpretation of data; in the writing of the manuscript; and in the decision to submit the manuscript for publication". The trial whose data this study used was registered at Clinicaltrials.gov as NCT00648232, first registered March 28, 2008.

\section{Author details}

'University of California, San Francisco, Box 0886, San Francisco, CA 94143-0886, USA. ${ }^{2}$ Makerere University, Kampala, Uganda. ${ }^{3}$ Marie Stopes Uganda, Kampala, Uganda. ${ }^{4}$ Massachusetts General Hospital, Boston, MA, USA. ${ }^{5}$ University of California, Los Angeles, USA.

Received: 28 February 2014 Accepted: 10 July 2014

Published: 20 July 2014

\section{References}

1. World Health Organization: Global Status Report on Alcohol and Health. 2014. Retrieved from http://www.who.int/substance_abuse/publications/ global_alcohol_report/en/.

2. Hahn JA, Woolf-King SE, Muyindike W: Adding fuel to the fire: alcohol's effect on the HIV epidemic in Sub-Saharan Africa. Curr HIV/AIDS Rep 2011, 8(3):172-180.

3. Woolf-King SE, Maisto SA: Alcohol use and high-risk sexual behavior in Sub-Saharan Africa: a narrative review. Arch Sex Behav 2011, 40(1):17-42.

4. Kalichman SC, Simbayi LC, Kaufman M, Cain D, Jooste S: Alcohol use and sexual risks for HIV/AIDS in Sub-Saharan Africa: Systematic review of empirical findings. Prev Sci 2007, 8(2):141-151.

5. Fisher JC, Bang H, Kapiga SH: The association between HIV infection and alcohol use: a systematic review and meta-analysis of African Studies. Sex Transm Dis 2007, 34(11):856-863.

6. Woolf-King S, Steinmaus C, Reingold A, Hahn JA: An update on alcohol use and risk of HIV infection in sub-Saharan Africa: Meta-analysis and future research directions. Int J Alcohol Drug Res 2013, 2(1):99-110.

7. Santelli JS, Edelstein ZR, Mathur S, Wei Y, Zhang W, Orr MG, Higgins JA, Nalugoda F, Gray RH, Wawer MJ, Serwadda DM: Behavioral, biological, and demographic risk and protective factors for new HIV infections among youth in Rakai, Uganda. J Acquir Immune Defic Syndr 2013, 63(3):393-400.

8. Seeley J, Nakiyingi-Miiro J, Kamali A, Mpendo J, Asiki G, Abaasa A, De Bont J, Nielsen L, Kaleebu P, Team CS: High HIV incidence and socio-behavioral risk patterns in fishing communities on the shores of Lake Victoria, Uganda. Sex Transm Dis 2012, 39(6):433-439.

9. Vandepitte J, Weiss HA, Bukenya J, Nakubulwa S, Mayanja Y, Matovu G, Kyakuwa N, Hughes P, Hayes R, Grosskurth H: Alcohol use, mycoplasma genitalium, and other STIs associated With HIV incidence among women at high risk in Kampala, Uganda. J Acquir Immune Defic Syndr 2013, 62(1):119-126.

10. Fatch R, Bellows B, Bagenda F, Mulogo E, Weiser S, Hahn JA: Alcohol consumption as a barrier to prior HIV testing in a population-based study in rural Uganda. AIDS Behav 2013, 17(5):1713-1723.

11. Nelson S, Bagby GJ: Alcohol and HIV Infection. Trans Am Clin Climatol Assoc 2011, 122:244-253.

12. Hahn JA, Samet JH: Alcohol and HIV disease progression: weighing the evidence. Curr HIV/AIDS Rep 2010, 7(4):226-233.

13. Conen A, Wang Q, Glass TR, Fux CA, Thurnheer MC, Orasch C, Calmy A, Bernasconi E, Vernazza P, Weber R, Bucher HC, Battegay M, Fehr J: Association of alcohol consumption and HIV surrogate markers in participants of the Swiss HIV Cohort Study. J Acquir Immune Defic Syndr 2013, 64(5):472-478.

14. Baum MK, Rafie C, Lai S, Sales S, Page JB, Campa A: Alcohol use accelerates HIV disease progression. AIDS Res Hum Retroviruses 2010, 26(5):511-518.

15. Hendershot CS, Stoner SA, Pantalone DW, Simoni JM: Alcohol use and antiretroviral adherence: review and meta-analysis. J Acquir Immune Defic Syndr 2009, 52(2):180-202.

16. Bhat VG, Ramburuth M, Singh M, Titi O, Antony AP, Chiya L, Irusen EM, Mtyapi PP, Mofoka ME, Zibeke A, Chere-Sao LA, Gwadiso N, Sethathi NC, Mbondwana SR, Msengana M: Factors associated with poor adherence to anti-retroviral therapy in patients attending a rural health centre in South Africa. Eur J Clin Microbiol Infect Dis 2010, 29(8):947-953.

17. Do NT, Phiri K, Bussmann H, Gaolathe T, Marlink RG, Wester CW: Psychosocial factors affecting medication adherence among HIV-1 infected adults receiving combination antiretroviral therapy (cART) in Botswana. AIDS Res Hum Retroviruses 2010, 26(6):685-691.

18. Kader R, Seedat S, Govender R, Koch JR, Parry CD: Hazardous and harmful use of alcohol and/or other drugs and health status among South African patients attending HIV clinics. AIDS Behav 2013, 18(3):525-534.

19. Haberer JE, Baeten JM, Campbell J, Wangisi J, Katabira E, Ronald A, Tumwesigye E, Psaros C, Safren SA, Ware NC, Thomas KK, Donnell D, Krows M, Kidoguchi L, Celum C, Bangsberg DR: Adherence to antiretroviral prophylaxis for HIV prevention: a substudy cohort within a clinical trial of serodiscordant couples in East Africa. PLoS Med 2013, 10(9):e1001511.

20. Van Geertruyden JP, Woelk G, Mukumbi H, Ryder R, Colebunders R: Alcohol and antiretroviral adherence? What about Africa? I Acquir Immune Defic Syndr 2010, 54(4):e10.

21. Pefura-Yone EW, Soh E, Kengne AP, Balkissou AD, Kuaban C: Nonadherence to antiretroviral therapy in Yaounde: prevalence, determinants and the concordance of two screening criteria. $J$ Infect Public Health 2013, 6(4):307-315.

22. Jaquet A, Ekouevi DK, Bashi J, Aboubakrine M, Messou E, Maiga M, Traore HA, Zannou MD, Guehi C, Ba-Gomis FO, Minga A, Allou G, Eholie SP, Bissagnene E, Sasco AJ, Dabis F: Alcohol use and non-adherence to antiretroviral therapy in HIV-infected patients in West Africa. Addiction 2010, 105(8):1416-1421.

23. Naidoo P, Peltzer K, Louw J, Matseke G, McHunu G, Tutshana B: Predictors of tuberculosis (TB) and antiretroviral (ARV) medication non-adherence in public primary care patients in South Africa: a cross sectional study. BMC Public Health 2013, 13:396.

24. Deribe K, Hailekiros F, Biadgilign S, Amberbir A, Beyene BK: Defaulters from antiretroviral treatment in Jimma University Specialized Hospital. Southwest Ethiopia Trop Med Int Health 2008, 13(3):328-333.

25. Santos GM, Emenyonu NI, Bajunirwe F, Rain Mocello A, Martin JN, Vittinghoff E, Bangsberg DR, Hahn JA: Self-reported alcohol abstinence associated with ART initiation among HIV-infected persons in rural Uganda. Drug Alcohol Depend 2014, 134:151-157.

26. Cook RL, Zhu F, Belnap BH, Weber K, Cook JA, Vlahov D, Wilson TE, Hessol NA, Plankey M, Howard AA, Cole SR, Sharp GB, Richardson JL, Cohen MH: Longitudinal trends in hazardous alcohol consumption among women 
with human immunodeficiency virus infection, 1995-2006. Am J Epidemiol 2009, 169(8):1025-1032

27. Mackenzie C, Kiragu K, Odingo G, Yassin R, Shikuku P, Angala P, Sinkele W, Akinyi $\mathrm{M}$, Kilonzo N: The feasibility of integrating alcohol risk-reduction counseling into existing VCT services in Kenya. Afr J Drug Alcohol Stud 2009, 8(2):73-80.

28. Centers for Disease Control and Prevention (CDC): Revised Guidelines for HIV Counseling, Testing, and Referral. In MMWR. Morbidity and Mortality Weekly Report. Edited by Prevention CfDCa. 2001. Retrieved from http://www.cdc.gov/mmwr/preview/mmwrhtml/rr5019a1.htm.

29. The Voluntary HIV-1 Counseling and Testing Efficacy Study Group: Efficacy of voluntary HIV-1 counselling and testing in individuals and couples in Kenya, Tanzania, and Trinidad: a randomised trial. The Voluntary HIV-1 Counseling and Testing Efficacy Study Group. Lancet 2000, 356(9224):103-112

30. Wanyenze RK, Kamya MR, Fatch R, Mayanja-Kizza H, Baveewo S, Szekeres G, Bangsberg DR, Coates T, Hahn JA: Abbreviated HIV counselling and testing and enhanced referral to care in Uganda: a factorial randomised controlled trial. Lancet Global Health 2013, 1(3):e137-e145.

31. Bush K, Kivlahan DR, McDonell MB, Fihn SD, Bradley KA: The AUDIT alcohol consumption questions (AUDIT-C): an effective brief screening test for problem drinking. Ambulatory Care Quality Improvement Project (ACQUIP). Alcohol Use Disorders Identification Test. Arch Intern Med 1998, 158(16):1789-1795.

32. Filmer D, Pritchett LH: Estimating wealth effects without expenditure data-or tears: an application to educational enrollments in states of India. Demography 2001, 38(1):115-132.

33. Meltzer $\mathrm{H}$ : Development of a Common Instrument for Mental Health. In EUROHIS: Developing Common Instruments for Health Surveys Edn. Edited by Nosikov A, Gudex C. Amsterdam: IOS Press; 2005:35-60.

34. Baveewo S, Kamya MR, Mayanja-Kizza H, Fatch R, Bangsberg DR, Coates T, Hahn JA, Wanyenze RK: Potential for false positive HIV test results with the serial rapid HIV testing algorithm. BMC Res Notes 2012, 5:154.

35. Bursac Z, Gauss CH, Williams DK, Hosmer DW: Purposeful selection of variables in logistic regression. J Source Code Biol Med 2008, 3:17.

36. Stata Multiple Imputation Reference Manual: Release 13. http://www.stata. com/manuals13/mimitest.pdf.

37. Neighbors C, Dillard AJ, Lewis MA, Bergstrom RL, Neil TA: Normative misperceptions and temporal precedence of perceived norms and drinking. J Stud Alcohol 2006, 67(2):290-299.

38. Tumwesigye NM, Kasirye R, Nansubuga E: Is social interaction associated with alcohol consumption in Uganda? Drug Alcohol Depend 2009, 103(1-2):9-15.

39. Ludwig AM: Cognitive processes associated with "spontaneous" recovery from alcoholism. J Stud Alcohol 1985, 46(1):53-58.

40. Smart RG: Spontaneous recovery in alcoholics: a review and analysis of the available research. Drug Alcohol Depend 1976, 1(4):277-285.

41. Satre DD, Gordon NP, Weisner C: Alcohol consumption, medical conditions, and health behavior in older adults. Am J Health Behav 2007, 31(3):238-248.

42. Saitz R: Lost in translation: the perils of implementing alcohol brief intervention when there are gaps in evidence and its interpretation. Addiction 2014, in press.

43. Saitz R, Horton NJ, Larson MJ, Winter M, Samet JH: Primary medical care and reductions in addiction severity: a prospective cohort study. Addiction 2005, 100(1):70-78.

44. Tsai AC, Bangsberg DR, Bwana M, Haberer JE, Frongillo EA, Muzoora C, Kumbakumba E, Hunt PW, Martin JN, Weiser SD: How does antiretroviral treatment attenuate the stigma of HIV? Evidence from a cohort study in rural Uganda. AIDS Behav 2013, 17(8):2725-2731.

45. Weiser SD, Gupta R, Tsai AC, Frongillo EA, Grede N, Kumbakumba E, Kawuma A, Hunt PW, Martin JN, Bangsberg DR: Changes in food insecurity, nutritional status, and physical health status after antiretroviral therapy initiation in rural Uganda. J Acquir Immune Defic Syndr 2012, 61(2):179-186.

46. Martinez P, Tsai AC, Muzoora C, Kembabazi A, Weiser SD, Huang Y, Haberer JE, Martin JN, Bangsberg DR, Hunt PW: Reversal of the Kynurenine pathway of tryptophan catabolism may improve depression in ART-treated HIVinfected Ugandans. J Acquir Immune Defic Syndr 2014, 65(4):456-462.

47. Maisto SA, Clifford PR, Davis CM: Alcohol treatment research assessment exposure subject reactivity effects: part II. Treatment engagement and involvement. J Stud Alcohol Drugs 2007, 68(4):529-533.
48. Sander PM, Cole SR, Ostrow DG, Mehta SH, Kirk GD: Determinants of alcohol consumption in HIV-uninfected injection drug users. Drug Alcohol Depend 2010, 111(1-2):173-176

49. Papas RK, Gakinya BN, Baliddawa JB, Martino S, Bryant KJ, Meslin EM, Sidle JE: Ethical issues in a stage 1 cognitive-behavioral therapy feasibility study and trial to reduce alcohol use among HIV-infected outpatients in western Kenya. J Empir Res Hum Res Ethics 2012, 7(3):29-37.

50. Hahn JA, Bwana MB, Javors MA, Martin JN, Emenyonu NI, Bangsberg DR: Biomarker testing to estimate under-reported heavy alcohol consumption by persons with HIV initiating ART in Uganda. AIDS Behav 2010, 14(6):1265-1268.

51. Hahn JA, Fatch R, Kabami J, Mayanja B, Emenyonu NI, Martin J, Bangsberg DR: Self-report of alcohol use increases when specimens for alcohol biomarkers are collected in persons with HIV in Uganda. J Acquir Immune Defic Syndr 2012, 61(4):e63-e64.

52. World Health Organization: ATLAS of Substance Use Disorders. Resources for the Prevention and Treatment of Substance Use Disorders (SUD). Country Profile: UGANDA. In 2010. Retreived from http://www.who.int/ substance_abuse/publications/atlas_report/profiles/uganda.pdf.

53. Vandepitte J, Bukenya J, Weiss HA, Nakubulwa S, Francis SC, Hughes P, Hayes R, Grosskurth H: HIV and other sexually transmitted infections in a cohort of women involved in high-risk sexual behavior in Kampala, Uganda. Sex Transm Dis 2011, 38(4):316-323.

54. Kekwaletswe CT, Morojele NK: Alcohol use, antiretroviral therapy adherence, and preferences regarding an alcohol-focused adherence intervention in patients with human immunodeficiency virus. Patient Prefer Adherence 2014, 8:401-413.

55. Weiser SD, Leiter K, Heisler M, McFarland W, Percy-de Korte F, DeMonner SM, Tlou S, Phaladze N, lacopino V, Bangsberg DR: A population-based study on alcohol and high-risk sexual behaviors in Botswana. PLOS Med 2006, 3(10):e392.

56. O'Donnell A, Anderson P, Newbury-Birch D, Schulte B, Schmidt C, Reimer J, Kaner $\mathrm{E}$ : The impact of brief alcohol interventions in primary healthcare: a systematic eview of reviews. Alcohol Alcohol (Oxford, Oxfordshire) 2014, 49(1):66-78.

doi:10.1186/1471-2334-14-403

Cite this article as: Hahn et al:: Decreases in self-reported alcohol consumption following HIV counseling and testing at Mulago Hospital, Kampala, Uganda. BMC Infectious Diseases 2014 14:403.

\section{Submit your next manuscript to BioMed Central and take full advantage of:}

- Convenient online submission

- Thorough peer review

- No space constraints or color figure charges

- Immediate publication on acceptance

- Inclusion in PubMed, CAS, Scopus and Google Scholar

- Research which is freely available for redistribution 